\title{
The Traditional Architecture of the Melanau Tall Longhouse, Mukah, Sarawak
}

\author{
Azizi Bahauddin ${ }^{1,}$ and Dyg Mustika Syaheeda Awg Musadat ${ }^{2}$ \\ ${ }^{1,2}$ School of Housing, Building and Planning, Universiti Sains Malaysia, Penang, Malaysia
}

\begin{abstract}
Full of history and legends, the Melanau, one of the ethnic groups of Mukah, Sarawak, Borneo, went through a few periods of cultural assimilation. Three major areas: the Tellian Daya (Ulu), Tellian Puloh and Tellian Laut communities, are the main enclaves of these people with Tellian Puloh being the main hub. Their settlements along the river banks are in lowlands within the tidal zone. During the monsoon period (lian suluh), the tides combined with the flood water from the hills produce unpredictable fluctuations of high and low water and flooding creating a saturated bog like quality. This paper aims to investigate the Melanau tall longhouse. Its construction was built in such tall heights due to the conditions of the soft soil. Often known to have been built up to 40 feet high, the house also provides protection for the people from floods as well as what used to be their enemies of other warring tribes. The materials used for the construction of the house came from the surrounding areas of sago leaves for the roof, sago tree trunk that had been sliced into planks for walls, nibong tree trunks for the floor and belian (Bornean iron wood) tree trunks for the main structural components of the house. All of these materials are known to be hardy and water resistance. Unfortunately, these traditional houses no longer exist with a few being abandoned and left to rot. Architectural documentation of this house is urgently needed to record the historical part of this culture. The investigation takes on qualitative method looking into the cultural influence onto the architecture. Survey, observation, architectural documentation and interviews with the Melanau cultural experts were undertaken. The finding pointed towards the establishment of the architectural language of the house based on the culture influence and functions of the spaces.
\end{abstract}

\section{Introduction}

Sarawak (Fig. 1) is the largest state in Malaysia (Fig. 2) and known by its various ethnic groups. Among ethnic groups in Sarawak are Malay, Chinese, Indian, Iban, Bidayuh and Melanau. The Melanau is viewed among the earliest settlers in Sarawak and is the fourth Sarawak predominant ethnic, after Malay, Iban and Bidayuh. The Melanau live alongside the lower reaches of the Rajang River, the well-known river in Sarawak, and spread alongside the coast from the mouth of the Rajang northeast, to Bintulu, and from the coast of Kanowit. Due to that, they call themselves a-likow, meaning 'people of the river'. 


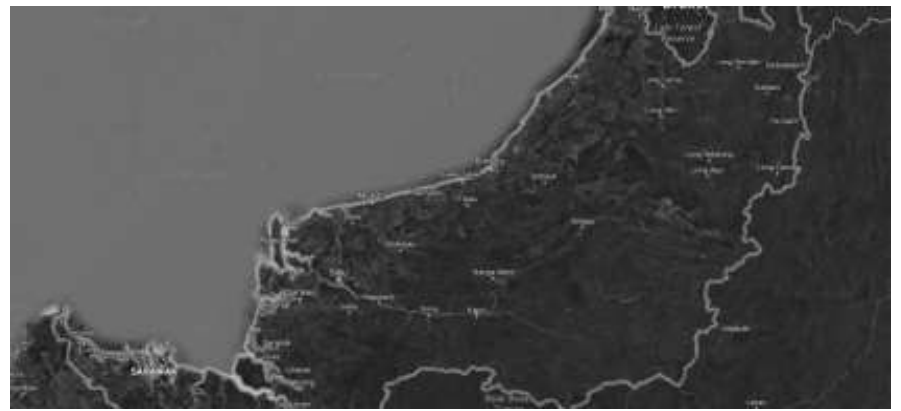

Fig.1. Map of Sarawak

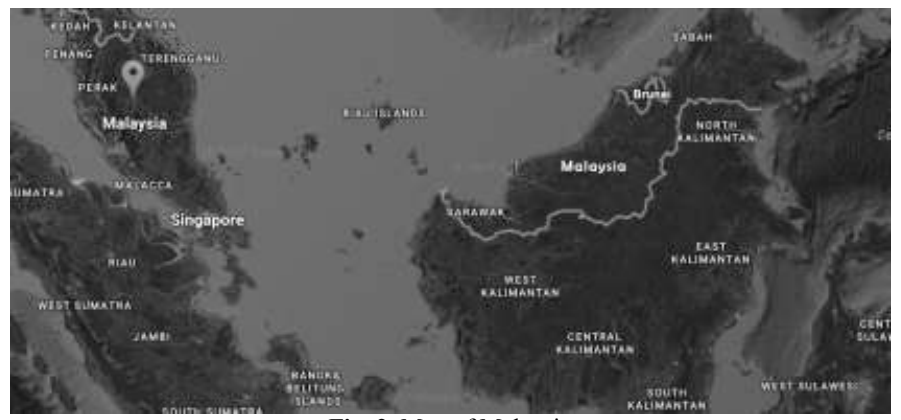

Fig. 2. Map of Malaysia

In ancient times, the Melanau used to stay in tall and prolonged houses, but nowadays, they live in Malaysian kampung-style properties. The Melanau traditional house often known to be 40 feet high from the ground and built by using solid belian, nibong and sago tree trunks. In the past, a hamlet of Melanau usually consist of one to three tall longhouses, located in strategic position; at the river mouth within the tidal zone by taking into consideration the security and economic activities. The Melanau community worked as boat builders. However, their main jobs are as padi farmers, fisherman and most importantly, as sago farmers [1]. The sago trees commonly found in freshwater swamps around Mukah, Oya, and Dalat. Since the Melanau have constantly been the most distinguished inhabitants of the southwest coastal area, in order to manipulate the revenue from the sago trade, as early as 400 years in the past, the Sultanate of Brunei appointed Melanau representatives at the mouths of the most necessary sago-producing rivers, especially Oya River and Mukah River [2].

\section{Methodology}

The research utilized a qualitative method relying on ethnography and phenomenology documentation upheld by a top to bottom examination in the Tellian Puloh, Mukah. It will be supported by looking into the cultural influence onto the architectural language of the Melanau Tall Longhouse. Data obtained through observation, architectural documentation on the longhouse and interviews with the Melanau cultural experts. Architectural documentation of this house is urgently needed to record the historical part of this culture. Therefore, background research on few recognizes longhouses conducted before further work can occur. Nonetheless, the absence of optional information requires the analyst to rely on primary sources. This research included few non-structured interviews with few longhouses owner at Tellian Puloh. This procedure ran at the same time with the visual information accumulation on their traditional house and ways of living. For this paper, only a single case study explored which is the Melanau Tall Longhouse in Sarawak Cultural Village. This process will capture the architectural language of an actual Melanau Tall Longhouse. 


\section{The Melanau Community}

Melanau ethnic is believed to have originated from the island of Java as their traditional clothes seem to have Java influences. From the aspects of the spoken language and the practice of pre-Islam, Melanau ethnic shows similarity with the Orang Ulu ethnic; Sekapan, Lahanan, Punan Ba, Kanowit from Belaga in Hulu Rejang, Kanowit and Tanjung in Central Rejang. Melanau have their own spoken language with vary dialect and they can be differentiated among themselves through their dialect. Although each community has its own attribute dialect, they all share the equal cultural and lingual background. However, there is a small percentage of this community speak local Malay dialect. This group of Melanau is all Muslims. They embrace the Malay's way of life, yet some of the Melanau cultures are still being practiced. Melanau dialect was usually used as a part of discussion and their traditional use freely either in entertainment or singing.

Years ago, the Melanau practiced animist religion before Islam and Christian religions came to Sarawak. Islam religion spread throughout the Melanau region; Mukah, Oya, Dalat, Matu, Rejang, Sibu, Igan, Sarikei, Tatau, Bintulu and Balingian; by the Sultanate of Brunei. The Melanau embraced Islam because they were captivated by the teachings of Islam and it was also a part of the basis ruling, to respect the Sultanate [3]. With regard to Christianity, the religion spread through the expansion of British rule in Sarawak. The British built churches at each region, Catholic schools monitored by Fathers, Mothers, and Sisters, along with introducing the tax system [4].

Whilst the Melanau was originally animist follower, a majority of the Melanau nowadays are Muslim, although some of them, particularly among the Melanau Mukah, and Dalat are Christian. In spite of that, most of the Melanau still practice their ancestor traditional rites such as the Kaul Festival. In spite of their different beliefs and religions, the Melanau are very tolerant among themselves. One can still come across a Melanau family with different family members embracing different religions whilst their parents nonetheless have robust animist beliefs.

\section{Case Study- Melanau Tall Longhouse, Sarawak Cultural Village}

Due to the fact that these traditional houses no longer exist within Tellin Puloh perimeter, with a few being abandoned, a Melanau Tall Longhouse model in Sarawak Cultural Village (Fig. 3) is chosen as the main site for this case study. Even though it was built for tourism purposes and is located in the Kuching City, through first observation, the overall architectural language of the model can be considered authentic.

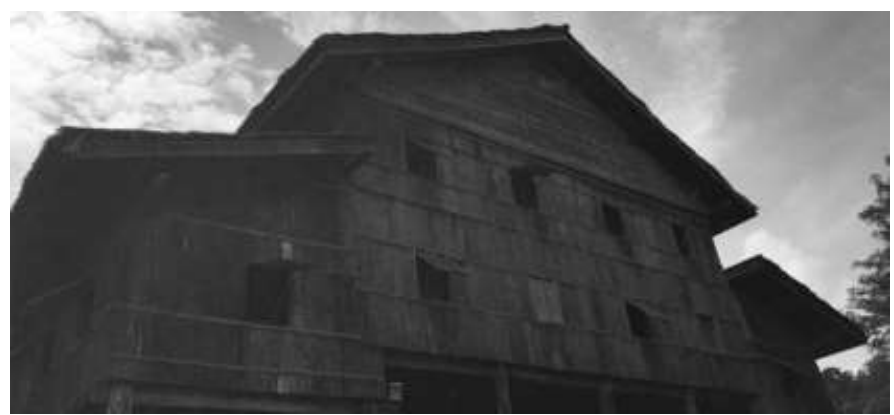

Fig. 3. Melanau Tall Longhouse, Sarawak Cultural Village

The Melanau traditional house is a type of a longhouse but it is famously known by its' height. Therefore, it is named as the tall longhouse and consists of three levels; first level, main level, and upper level. The Melanau Tall Longhouse model in Sarawak Cultural Village is a living museum that is located at the foothills of Mount Santubong, about 35 $\mathrm{km}$ from Kuching. Besides functioning as a living museum, the management provides an area that function as a homestay for tourists all around the world. Every area of the house is loaded with tradition artifact belonged to the Melanau tribe. The structures of this house built using conventional materials which are readily available from the 
jungle and all of these materials are known to be hardy and water resistance. Belian tree trunks used as the main structural components of this house especially for the columns (Fig. 4) and the stairs. The wall structure and flooring are made out of nibong tree trunks. Lastly, the main economical source for the Melanau community, sago leaves, is use to build the roof, while the trunks will be sliced into planks and can be used as a part of the wall materials.

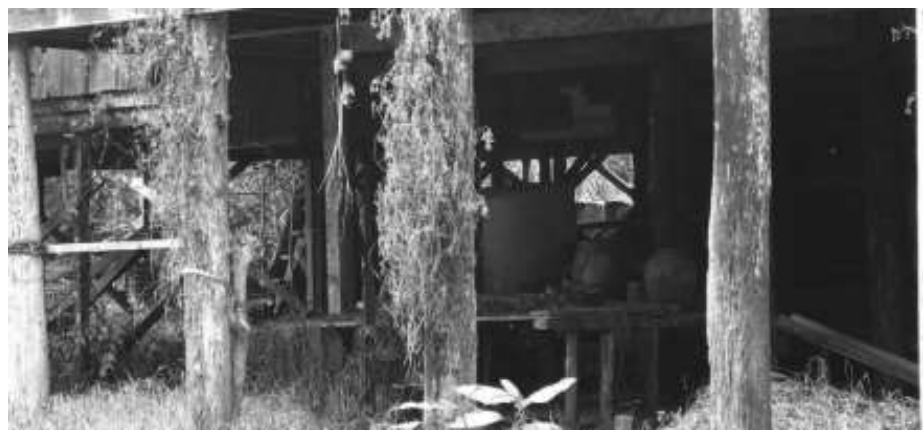

Fig. 4. Solid Belian Tree Trunks as Columns

Melanau Tall Longhouse has its own historical background, contradict to other traditional longhouses in Sarawak. The building structure and height can be named as part of the uniqueness of this building. Unlike other traditional longhouses in Sarawak, Melanau Tall Longhouse (Fig. 5 and 6) is built 40 feet high from the ground and consists of 20 to 30 living spaces for each family staying at that tall longhouse [5].

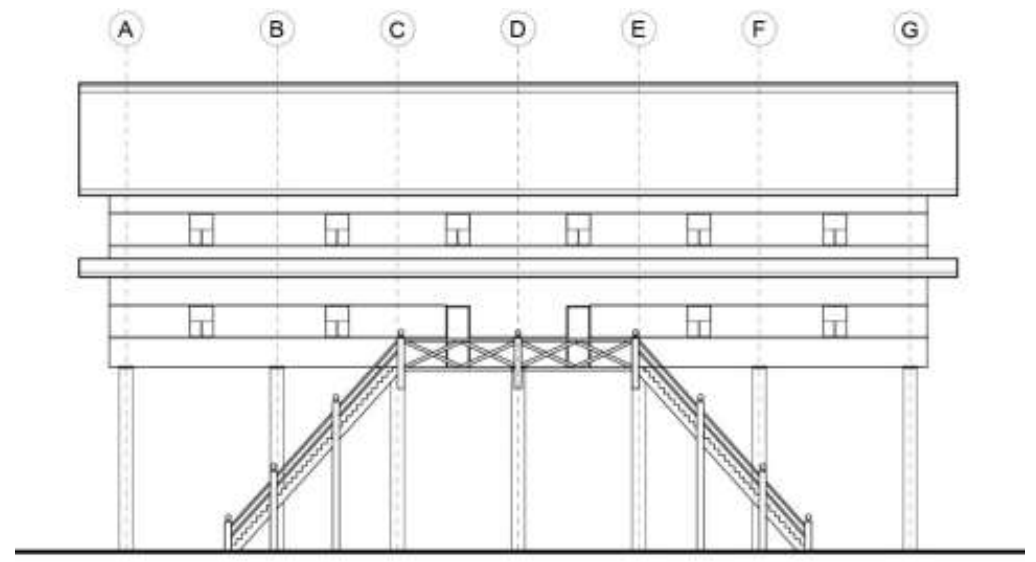

Fig. 5. Melanau Tall Longhouse Front Elevation 


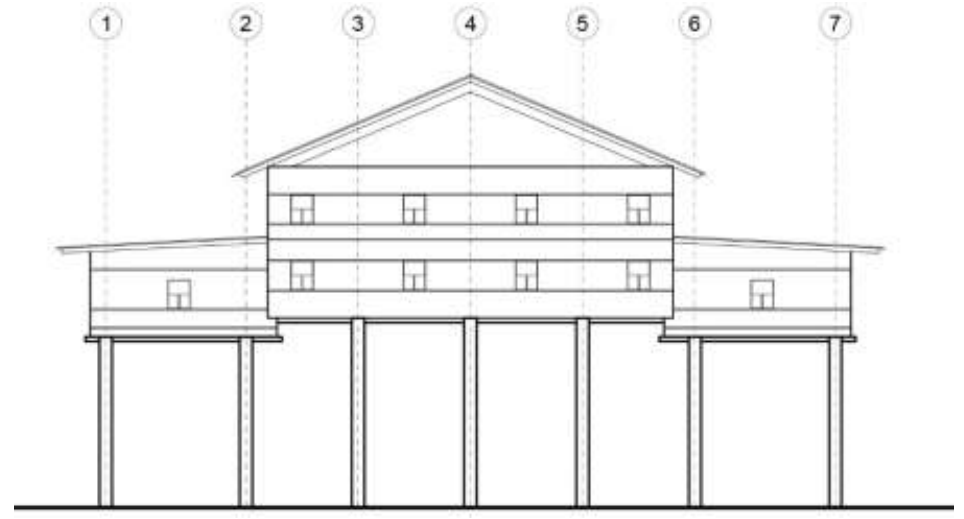

Fig. 6. Melanau Tall Longhouse Rear Elevation

Melanau traditional house flooring is made out of double layer nibong (Fig. 7) trunks and are arranged in a criss-cross pattern with tiny gaps in between, making sharp weapons such as lances and blades to hardly pass through. Those tiny gaps work as a part of the house protection from their enemies of other warring tribes, especially from the Headhunters, the Iban ethnics. The Melanau community will pour boiling water onto the floor when attacked by other tribes from below.

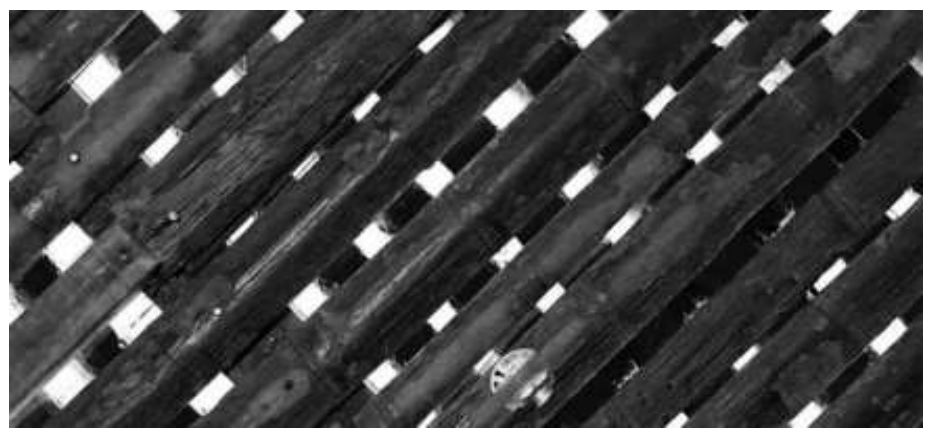

Fig. 7. Nibong Flooring 


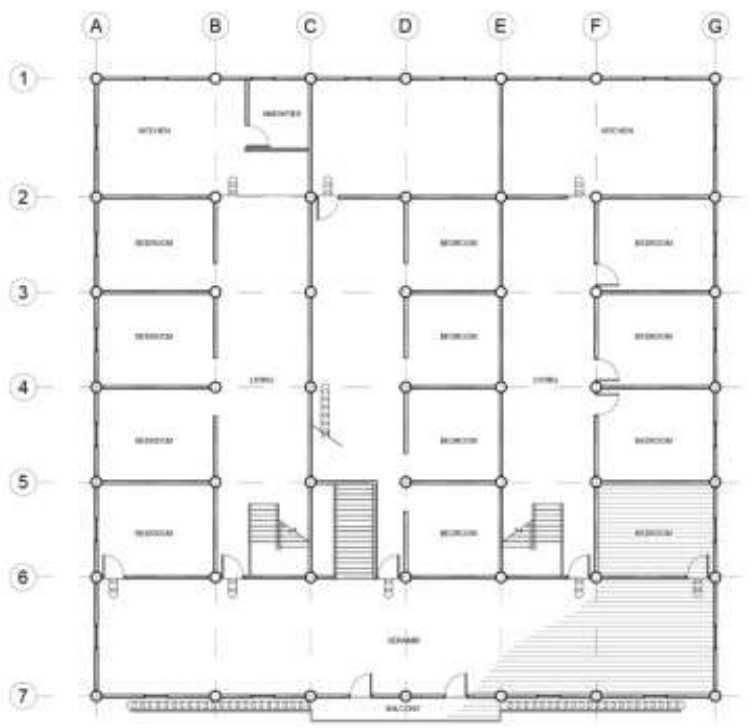

Fig. 8. Main Level Floor Plan

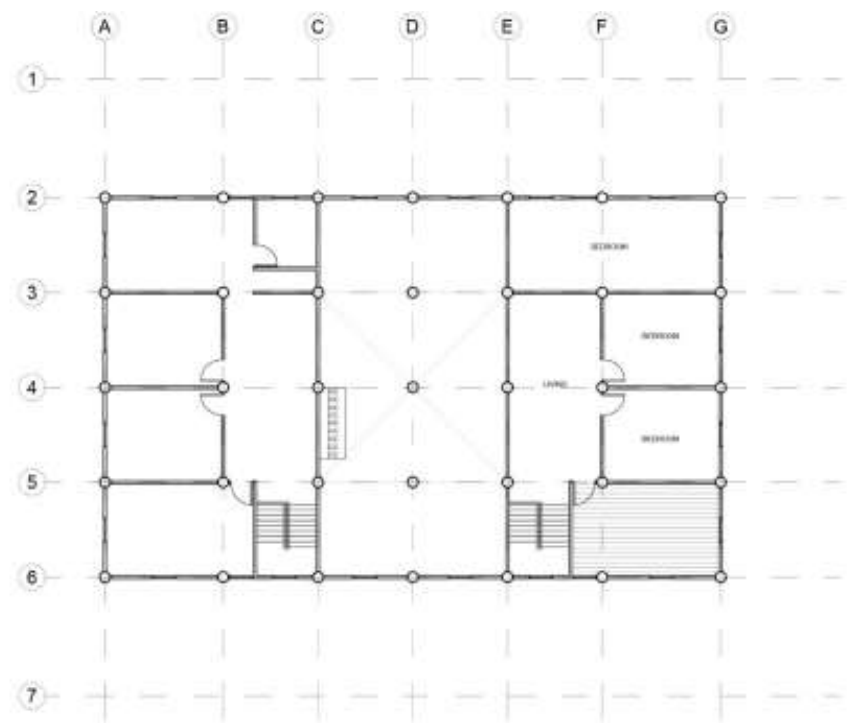

Fig. 9. Upper Level Floor Plan

The main floor (Fig. 8) of this house act as a mutual space for every family and is also where the kitchen is located. The centre space of this building function as the family area, where any types of ceremony from activity of life starting until the person is dead took place. Main floor consists of few rooms, 20 to 30 apartments, for every family that are staying in that tall longhouse. Next, the upper level (Fig. 9) is where the Melanau keep their tradition artifact and family's assets. 


\section{Conclusion}

This paper examines and analyses the longhouse associated with the Melanau Tall Longhouse as the focus of the study in relation to their traditional culture. The research looks into the understanding of their unique longhouse which is differ to other longhouses in Sarawak. The complex nature of the Melanau community established the concepts of sharing and cooperation within the overall layout design of the Melanau Tall Longhouse. It is cultural conventions and cues that control the information linking social organisation with the built environment with the adoption of local materials as the main structure of the building. Regardless of its extinction, the interpretation received from the overall view on its architectural language has demonstrated the meaning of this longhouse from top to bottom and the importance of having a sheltered for this ethnic family. The Melanau convention culture offers boundless legacy values that are valuable for the general population and also guests to comprehend this unique group.

\section{Acknowledgement}

The authors would like to thanks Ministry of Higher Education of Malaysia for providing Fundamental Research Grant Scheme (FRGS - 203 / PPBGN / 6711554) to support this study. The credit also goes to the School of Housing, Building and Planning, Universiti Sains Malaysia for providing facilities to carry out the work.

\section{References}

1. S. Baring-Gould, and C.A. Bampfylde, A history of Sarawak: under its two white rajahs, 1839-1908, 20 (2007)

2. S. Morris, The Oya Melanau., (1978)

3. P.L. Amin Sweeney, Journal of the Malaysian Branch of the Royal Asiatic Society, Silsilah Raja-raja Brunei, 182 (1968)

4. Dzulfawati Hassan, Upacara Kematian Melanau Likow di Sarawak, (2006)

5. V.F. Chen, The Encyclopaedia of Malaysia: Architecture, (1998) 